\title{
LA IGUALDAD ENTRE MUJERES Y HOMBRES EN LA CONSTITUCIÓN ESPAÑ̃LA DE 1978
}

Má ÁNGELES MORAGA GARCÍA Universidad de Alicante

La igualdad entre mujeres y hombres es un principio constitucionalmente reconocido en nuestro ordenamiento jurídico. Sin embargo la realidad viene a demostrar continuamente la persistencia de importantes escenarios de desigualdad por razón de género, que sitúan a las mujeres en una posición de desventaja, cuando no de clara inferioridad, frente a la de los hombres.

No es una afirmación tópica o gratuita, cualquiera puede verificarla con la simple observación de su entorno familiar, social, laboral, etc. A continuación, citaré algunos ejemplos que vienen a corroborar la situación de desigualdad que continua sufriendo la mujer en nuestro país actualmente:

- España es el cuarto país de la Unión Europea con menor proporción de mujeres que trabajan fuera de casa mientras tienen hijos menores de 12 años. Así lo demuestra un estudio de la oficina estadística comunitaria, EUROSTAT, elaborado el pasado año 2005. A tenor de ese trabajo, la tasa de empleo entre las españolas con niños pequeños alcanza el $51,2 \%$, frente al $60,4 \%$ de media comunitaria. Sólo sobrepasan este índice las madres de Italia, Hungría y Malta.

- En nuestro país, cerca de 400.000 mujeres abandonan su empleo cada año por razones personales o para asumir responsabilidades familiares, según el Instituto Nacional de Estadística. En concreto en el año 2004, dieron ese paso 379.500 trabajadoras, según revela la Encuesta de Población Activa. Mientras que entre los trabajadores varones sólo tomaron esa decisión un total de 14.500 .

- El salario medio de la mujer en España es un 34,7 \% inferior al del hombre, según el informe sobre el mercado laboral publicado por la empresa de trabajo temporal Manpower en el mes de enero de 2005. La menor desigualdad tiene lugar en aquellas compañías de 20 a 49 trabajadores en las que los hombre ganan de media un 13,8\% más que las mujeres, mientras que son las empresas de 100 a 499 trabajadores las que presen- 
$\tan$ las mayores diferencias salariales ente sexos (hasta un 50\%, siempre a favor del hombre).

Asimismo este estudio indica que en el año 2001 el sueldo medio de la mujer en el sector privado era sólo de 992 euros brutos al mes, un $50 \%$ menos que el del hombre, que ascendía a 1.489 euros. Estas diferencias salariales se reducen hasta el $44 \%$ en los niveles educativos más altos, mientras que en los niveles inferiores el salario de la mujer se sitúa un $56 \%$ por debajo. De igual manera, el estudio señala que la desigualdad se acrecienta a medida que aumentan los años de experiencia laboral. En este caso, mientras que las mujeres con experiencia de entre 5 y 29 años cobran entre un $12 \%$ y un $28 \%$ menos que el hombre, a partir de los 29 años de experiencia el salario del hombre llega a ser un $73 \%$ superior.

- He aquí un ejemplo paradigmático: nuestro país tiene, desde hace dos años, el primer Gobierno paritario de la historia, contando a su vez con la primera Vicepresidenta del Gobierno. Sin embargo, la paridad no se traslada a los sucesivos niveles del poder. Según datos del Instituto Nacional de Estadística correspondientes a 2004, sólo hay un $15 \%$ de Secretarias de Estado (3 entre 17) y un 23\% de Directoras Generales. Esta desigualdad se dispara en las Delegaciones del Gobierno, donde el desequilibrio crece sensiblemente: 2 mujeres Delegadas del Gobierno, frente a 17 hombres, lo que supone un $10 \%$.

- Si nos adentramos en la representación exterior del Estado y atendiendo a los datos del propio Ministerio de Asuntos Exteriores, en España hay una plantilla total de 800 Diplomáticos, de los cuales sólo 150 son mujeres.

Asimismo, de un total de 144 embajadores destinados en delegaciones diplomáticas o en misiones especiales, sólo 12 son embajadoras -un 7,7\%-. Ahondando en el ejemplo, en lo que llevamos del año 2006, sólo se ha nombrado una embajadora, mientras que se han designado seis embajadores, todos ellos con sede diplomática en distintos países, mientras que la embajadora lo es en misión especial.

- En la política local la realidad no es más esperanzadora: Tras las elecciones locales de 2003, en nuestro país se proclamaron 15.443 concejalas frente a 41.048 concejales -según datos del INE-. Eso supone que únicamente un $27 \%$ de los regidores municipales mujeres. Alcaldesas hay aún menos (un 12,48\%).

- Otra tanto podemos constatar en la Justicia. A la luz de los datos del INE de 2004, hay 4.451 jueces y magistrados en activo. De ellos, el 44,80\% son mujeres, pero la mayoría ejerce sus funciones en el escalón más bajo, el de jueces, donde son más que hombres (64,13\%). Sin embargo sólo hay un $10 \%$ de mujeres entre los vocales del Consejo General del Poder Judicial y un $23 \%$ en el Tribunal Constitucional.

- En los Consejos de Administración de las empresas que cotizan en bolsa incluidas en el IBEX 35 -según datos del Instituto Nacional de la Mujer, año 2005- no había ninguna presidenta, y sólo un 2,32\% de los puestos de consejero eran ocupados por mujeres. 
- Otro ejemplo, en este caso del mundo de la cultura y de la ciencia: De las diez Reales Academias Españolas, sólo la de Farmacia supera los dos dígitos en cuanto al porcentaje de representación femenina $(12 \%$ de mujeres), siendo que en dos de ellas no se sienta ninguna mujer en sus sillones: en la Real Academia de Ciencias Veterinarias y en la Real Academia de Ciencias Políticas y Morales. Al parecer no hay mujeres capaces de alcanzar tales responsabilidades en nuestro país.

- En el ámbito universitario, a pesar de que la población universitaria de mujeres supera a la de los hombres, (54\%) y cada año se gradúan más alumnas $(59,10 \%)$ que alumnos, según datos del Ministerio de Educación. A medida que avanza el escalafón académico, la presencia de las mujeres se va perdiendo, así de las 8.619 cátedras de universidad sólo el $13,7 \%$ tienen al frente a una mujer.

Todos los ejemplos expuestos no son anecdóticos, su persistencia en los inicios del siglo XXI viene a demostrar la pervivencia de patrones de desigualdad, que ponen en entredicho la tan proclamada igualdad entre mujeres y hombres. La igualdad sigue siendo un objetivo inalcanzado, que tiene una mayor presencia en los textos jurídicos que en la realidad social. Que esta realidad jurídica abra paso a una nueva realidad social, es un trabajo de todas y todos, por este motivo resulta necesario que continuemos insistiendo en esta trascendental reivindicación.

\section{ANTECEDENTES}

La consecución de la igualdad real o material es uno de los objetivos del Estado Social, reconocido en las Constituciones europeas de la segunda mitad del siglo XX. Sin embargo, como demuestran los ejemplos que anteceden, lo cierto es que la tan pretendida igualdad real entre mujeres y hombres queda bastante lejos aún.

Como muy bien destaca María Luisa Balaguer, haciendo referencia a características del constitucionalismo moderno señaladas por Carlos De Cabo, «el Estado social y democrático de Derecho es una conquista de la ciudadanía, cuya evolución en Europa se inicia en la segunda mitad del siglo XIX y no llega a implantarse hasta bien entrado el siglo XX. La positivación del derecho como garantía jurídica y su efectividad, junto al de la generalidad de la ley y la separación de poderes del Estado, son instrumentos que permiten el desarrollo de las democracias formales que se generan en ese periodo histórico. Pero todas estas instituciones y garantías no comprenden a las mujeres, que accederán formalmente a los derechos políticos con bastante retraso sobre los hombres, y que tendrán restringidos los derechos civiles hasta fechas relativamente recientes ${ }^{1}$.

El ordenamiento jurídico español, como el resto de los ordenamientos fruto del Estado Liberal, no fue una excepción, y privó a las mujeres de los derechos

1. BALAgUer, Ma Teresa: Mujer y Constitución. La construcción jurídica del género, Madrid, Feminismos, 2005, p. 81. 
alcanzados por este modelo de Estado. Resultando especialmente negativa la influencia del Código de Napoleón de 1805 en nuestro Código Civil, que dejó a la mujer una exigua capacidad jurídica, y además la supeditó al marido o al padre para la realización de cualquier tipo de negocio jurídico.

En esta línea, ninguno de los textos constitucionales españoles hasta 1931 hacía referencia alguna a la igualdad de trato sin discriminación por razón de sexo.

Fue precisamente la Constitución Republicana de 1931, tan avanzada en muchos aspectos, la que supuso también un importante avance para las mujeres, en la medida que por primera vez se reconoció la igualdad jurídica entre mujeres y hombres. En concreto, el artículo 25 de texto constitucional establecía expresamente que no podía "ser fundamento de privilegio jurídico la naturaleza, la filiación y el sexo».

Respecto a la participación política, su artículo 36 proclamaba que «los ciudadanos de uno y otro sexo, mayores de veintitrés años, tendrán los mismos derechos electorales conforme determinen las leyes», reconociendo con ello el derecho de voto para la mujer.

Asimismo, en su artículo 41 se reconocía el matrimonio civil, lo que a su vez permitió instaurar el divorcio a través de la Ley de 2 de marzo de 1932. Esta misma Ley reconoció, entre otros aspectos, la igualdad de los hijos, suprimiendo la distinción entre hijos legítimos e ilegítimos, además de incorporar el término "autoridad del padre y de la madre», frente a la clásica autoridad paterna, aceptándose también el mutuo consentimiento para obtener el divorcio.

Lamentablemente esta nueva situación constitucional tuvo una escasa vigencia, que tan solo alcanzó hasta el estallido de la Guerra Civil, en 1936. El triunfo del golpe militar encabezado por el general Franco supuso un retroceso de siglos en el camino de la ansiada igualdad.

Resulta evidente que la instauración de un régimen dictatorial y fascista necesariamente había de comportar la limitación y hasta la negación de derechos para todas las personas, hombres y mujeres, pero lo cierto es que el régimen franquista incidió de una manera significativa en la vuelta a la subordinación jurídica de estas últimas, aprobándose numerosas normas jurídicas que tenían por finalidad conseguir el sometimiento de las mujeres, a fin de devolver a la mujer a su posición tradicional.

En este sentido, se suprimiría la escuela mixta, se «liberaría» a la mujer casada del taller y del trabajo - una medida acompañada de primas por maternidad y prohibición del ejercicio de profesiones liberales-, se derogaría la ley del matrimonio civil y la ley del divorcio -con efectos retroactivos-, se penalizó el aborto, el adulterio y el concubinato. También se incrementó la mayoría de edad a los 25 años, obligando a la mujer joven a permanecer en el hogar paterno hasta el momento de casarse o entrar en el convento, etc.

En las leyes franquistas la familia se identificaba con el matrimonio católico, de tal manera que sólo aquellas familias legalizadas merecían protección jurídica. Este tratamiento repercutía directamente en los hijos, que según hubieran sido engendrados dentro o fuera del matrimonio, gozaban de más o menos derechos. Pero además, la familia no sólo era el lugar natural de las mujeres, 
sino que además ésta tenía un cabeza de familia, el marido, de tal forma que la mujer, cuando pasaba a formar parte de la familia, pasaba también a depender de la potestad del marido. El marido era quien tenía la potestad dentro del ámbito familiar y quien podía hacer y deshacer de acuerdo con lo que consideraba más oportuno. La ley le reconocía como el único interlocutor valido.

Por lo tanto, la desigualdad jurídica entre los cónyuges era evidente, existiendo la llamada licencia marital -que no fue derogada las la Ley 14/1975, de 2 de mayo- que obligaba a la mujer casada bajo régimen de gananciales -que era el que regia el derecho común- a que su marido firmara antes que ella autorizándole, por ejemplo, a abrir una cuenta corriente, solicitar un pasaporte, y firmar una escritura o cualquier contrato. Incluso con respecto a la disposición de sus bienes propios, la mujer casada necesitaba la autorización marital. Además el marido era el administrador único de la sociedad de gananciales atribuyéndole el Código Civil la facultad de enajenar, a titulo oneroso, los bienes de la sociedad de gananciales.

Asimismo el franquismo dedicó un especial énfasis a controlar todo lo relacionado con el comportamiento sexual de las personas, especialmente de las mujeres, lo que suponía tipificar en el Código Penal como delitos, situaciones que se calificaban de atentados al honor de las mujeres, y sobre todo, al de sus maridos. Se penalizaba el aborto, así como el uso de los anticonceptivos. También el Código Penal incluía un titulo especifico que se refería a los delitos contra la honestidad, donde se contemplaban las figuras jurídicas de la violación, los abusos deshonestos, el escándalo publico, el estupro, la corrupción de menores, el rapto y los delitos relativos a la prostitución.

Otro ámbito vedado a las mujeres era el mundo laboral, limitándose su acceso al trabajo remunerado. El trabajo de las mujeres se situaba en el ámbito doméstico y cuando realizaban trabajos remunerados o fuera del hogar, era un trabajo provisional y auxiliar con respecto al de los hombres.

Siendo lo cierto que durante los cuarenta años que duró la dictadura en España, prácticamente no se modificaron las leyes discriminatorias contra la mujer, a pesar de que tanto la normativa internacional como la de Comunidad Europea estaban dando pasos muy importantes en el reconocimiento de la igualdad de género.

Con este escenario, la aprobación de la actual Constitución de 1978 supuso un giro copernicano, un cambio radical, que respondía a las tendencias universales que reclamaban el reconocimiento de la igualdad de las mujeres y los hombres. Aunque lo cierto, como muy bien señala Asunción Ventura, es que el texto constitucional no contiene una mínima perspectiva de género, situando el derecho de la mujer a la igualdad en su artículo 14, junto con el resto de la interdicción de las desigualdades sociales².

2. VenturA, Asunción: Las Mujeres y la Constitución Española de 1978, Madrid, Instituto de la Mujer, 1999. 


\section{CONCEPTO DE IGUALDAD EN LA CONSTITUCIÓN}

La primera referencia a la igualdad en nuestra Constitución aparece, en el artículo 1.1 C., que se refiere a la igualdad como uno de los «valores superiores del ordenamiento jurídico", esto es, como una condición ideal, a la que los poderes públicos deben tender a alcanzar. Por lo tanto, dicho precepto sitúa a la igualdad como un valor superior que debe inspirar todo el ordenamiento jurídico.

De otra parte, en el artículo 9.2. del texto constitucional, aparece recogida la llamada "Igualdad Material», como un mandato dirigido a los poderes públicos que exige que se promuevan las condiciones para que la igualdad de los individuos y de los grupos en que se integran sean reales y efectivas. Con ello, se autoriza al legislador para desarrollar una acción igualizante, más allá de la mera igualdad formal.

Finalmente, el articulo 14 reconoce que los españoles son iguales ante la ley, sin que pueda prevalecer discriminación alguna, entre otras, por razón de sexo. Recogiéndose la llamada "Igualdad Formal», que se define en dos vertientes distintas: la igualdad ante la ley y la igualdad en la ley.

\subsection{La igualdad ante la Ley o en la aplicación de la Ley}

La igualdad ante la Ley puede definirse como la obligación que tienen los poderes públicos encargados de aplicar la ley, de aplicarla sin excepciones ni consideraciones personales. De esta forma el Tribunal Constitucional en su Sentencia 8/1981, de 30 de marzo señala que la igualdad en la aplicación de la ley impone que «un mismo órgano no puede modificar arbitrariamente el sentido de sus decisiones en casos sustancialmente iguales, y que cuando el órgano en cuestión considere que debe apartarse de sus precedentes tiene que ofrecer para ello una fundamentación suficiente y razonable».

Pero no obstante ello, el T.C. admite la diferencia de trato, en la aplicación de la Ley, cuando ésta no sea arbitraria por estar razonablemente justificada. De esta forma el propio Tribunal ha ido estableciendo una serie de requisitos que deben tenerse en cuenta para apreciar la existencia o no de desigualdad en la aplicación de la ley:

a) Que se trate de un mismo órgano judicial: Es doctrina reiterada del Tribunal Constitucional desde su inicio que «el principio de igualdad en la aplicación de la ley sólo puede ser invocado en caso de que las resoluciones aducidas procedan del mismo órgano judicial» (STC 2/1983, de 24 de enero, 105/87, de 22 de junio, 17/1988, de 20 de junio; 126/1988, de 24 de junio; 132/1988, de 4 de julio; 134/1991, de 17 de junio; 245/1994, de 15 de septiembre; 25/1999, de 8 de marzo; 32/1999, de 22 de abril; 59/2000, de 2 de marzo; 102/2000de 10 de abril; 122/2001, de 4 de junio y 140/2003, de 14 de julio, entre otras.

b) Que los supuestos de hecho sean idénticos, "pues sólo si los casos son iguales entre sí puede efectivamente pretenderse que la solución dada para uno 
sea igual a la del otro» (STC 140/2003, de 14 de julio, en la que se hace referencia numerosas sentencias anteriores que se pronuncian al respecto).

c) Que el cambio de criterio en la aplicación de la norma se base en una fundamentación suficiente y razonable: lo que no se permite es modificar el sentido de las decisiones de forma arbitraria, pero sí que se pueda variar el sentido de la resolución siempre y cuando se ofrezca una fundamentación suficiente y razonable en la que descasen dicho cambio de criterio. Así, la STC 142/1985, de 23 de octubre señala que será arbitraria aquella diferencia de trato que obedezca «a una deliberada modificación de los criterios de interpretación de la legalidad hasta entonces mantenidos, apreciable mediante cualquier elemento de juicio externo».

\subsection{La igualdad en la Ley o igualdad de trato}

La segunda vertiente de la igualdad formal que contempla el artículo 14, es la llamada Igualdad en la Ley o Igualdad de Trato, a fin de evitar situaciones de desigualdad entre los ciudadanos, lo que implica la prohibición de cualquier forma de arbitrariedad normativa.

Pero ese mandato de igualdad de trato, implica trato igual a situaciones iguales, lo que no impide diferencias de trato a situaciones diferentes. Tales diferencias de trato han de derivarse de diferencias de situación, que deben estar debidamente justificadas y ser razonables. En este sentido el Tribunal Constitucional ha establecido ciertos requisitos que sirven para determinar si una desigualdad de trato vulnera o no el mandato de igualdad formal del artículo 14 de la Constitución. Se trata del llamado «test o juicio de constitucionalidad»; que consiste en examinar, en cada caso concreto, si la diferencia de trato obedece a fines lícitos y relevantes, por un lado; y por otro, si esa diferencia de trato es proporcionada al fin perseguido.

Al legislador, por tanto, le está permitido establecer un trato distinto para los ciudadanos en aquellos casos en los que tenga que resolver situaciones de hecho diferentes, cuyo contenido exija una decisión distinta. En este sentido, el Tribunal Constitucional en su Sentencia 75/1983, de 3 de agosto, señala que "resulta indispensable que exista una justificación objetiva y razonable, de acuerdo con criterios y juicios de valor generalmente aceptados, cuya exigencia deba aplicarse en relación con la finalidad y efectos de la medida considerada, debiendo estar presente por ello una razonable relación de proporcionalidad entre los medios empleados y la finalidad perseguida, y dejando en definitiva al legislador con carácter general la apreciación de situaciones distintas que sea procedente diferenciar y tratar desigualmente, siempre que su acuerdo no vaya contra los derechos y libertades protegidos en los artículos 53.1 y 9.3 CE, ni sea irrazonada».

De esta forma, la jurisprudencia constitucional para determinar si una desigualdad de trato vulnera el mandato del articulo $14 \mathrm{C}$. ha basado su examen en el criterio de la razonabilidad; esto es, si la diferencia obedece a fines lícitos y relevantes, y si esa diferencia de trato es proporcionada al fin perseguido. Así lo establece la STC 155/1998, de 3 de agosto, en la que se afirma que «las 
diferencias normativas habrán de mostrar, en primer lugar, un fin discernible y legitimo; tendrán que articularse, además, en términos no inconsistentes con la finalidad y, deberán, por último, no incurrir en desproporciones manifiestas a la hora de atribuir a los diferentes grupos y categorías jurídicas, derechos y obligaciones o cualesquiera otras situaciones jurídicas subjetivas». En este mismo sentido se pronuncian las SSTC, de 3 de agosto; 222/1992, de 11 de diciembre; 158/1993, de 6 de mayo y 229/1999, de 28 de septiembre, entre otras.

\section{IGUALDAD Y DISCRIMINACIÓN}

El artículo 14 de nuestra Constitución, junto al principio de igualdad ante la ley, reconoce la prohibición de discriminación basada en determinadas causas especificadas en dicho precepto, entre las que se incluye el sexo.

Dicho mandato de no discriminación del articulo 14 debe interpretarse desde una doble vertiente que puede parecer paradójica, pero que resulta absolutamente complementaria: de un lado, como prohibición de trato desigual o principio general de igualdad; y de otro, desde una vertiente positiva que obliga a un trato desigual, en conexión con el art. 9.2, a fin de conseguir la igualdad real. Y ello con la finalidad de acabar con la histórica situación de marginación en la que social y jurídicamente se había situado a determinados grupos sociales.

De ahí, que haya ido apareciendo la llamada "Jurisprudencia Compensadora", que viene a aceptar y apoyar medidas que favorezcan a los grupos desfavorecidos, cuando éstas pretendan situar a dichos grupos en una posición efectivamente de igualdad, de forma tal que se justifican los tratos desiguales que traten de eliminar situaciones discriminatorias.

Respecto de las mujeres, tanto la realidad histórica como la realidad social de nuestros días, demuestran sin ningún género de duda que la discriminación se ha ejercido y se sigue ejerciendo contra el colectivo femenino, encontrándose profundamente arraigada en la sociedad.

Como muy bien señala Asunción Ventura, «el sexo ha sido, y sigue siendo, un factor de relevancia social que tiene implicaciones jurídicas desfavorables para las mujeres. Históricamente las mujeres han sido relegadas en la sociedad y esta marginación ha alcanzado la categoría de norma. Aunque actualmente no sucede de la misma manera, el sexo femenino sigue siendo un factor relevante que aparentemente no se tiene en cuenta, pero en la práctica resulta determinante para el desarrollo de las relaciones sociales y por tanto de las relaciones jurídicas. El sexo es un factor importante que sitúa a todas las mujeres en una categoría jurídica inferior en relación al hombre, por el simple hecho de pertenecer a ese grupo» ${ }^{3}$.

Por lo tanto, para avanzar en la igualdad, en primer lugar, resulta necesario que se considere a la mujer como un verdadero sujeto constitucional, lo que no ha venido ocurriendo. Ya que el derecho ha sido concebido desde su origen

3. VentuRA, Asunción: Op. cit., p. 159. 
por y para los hombres, habiendo creado un ordenamiento jurídico totalmente patriarcal, en el que las mujeres no han tenido cabida alguna.

Por ello, no es casual que la Constitución se limite, simplemente, a enumerar el sexo entre las categorías específicas citadas en el artículo 14 como causas prohibidas de discriminación, ilegitimando con ello toda diferenciación de trato basada en el sexo.

A este respecto, resulta preciso distinguir entre:

- Discriminación directa: que se produce cuando la diferencia de trato se vincula expresamente al sexo. El Tribunal Constitucional ha considerado discriminación directa el trato desfavorable dado a la mujer como consecuencia de una condición únicamente femenina, como por ejemplo, tratar de forma desfavorable el embarazo.

- Discriminación indirecta: en estos casos el trato desfavorable no aparece inmediatamente vinculado al sexo, pero en la práctica supone poner a la mujer en una posición desfavorable; como por ejemplo, que a efectos retributivos, se considere de menor valor aquel tipo de trabajo que es realizado por mujeres en forma casi totalmente exclusiva. Sirva como ejemplo la practica habitual de ofrecer una remuneración mayor a tareas realizadas por hombres, -como las de vigilancia y seguridad-, que las consideradas tradicionalmente femeninas, -limpieza-, aun cuando la duración, esfuerzo y atención de esas tareas fueran equivalentes.

Con ello, el Tribunal Constitucional viene a admitir que el principio de igualdad, ante determinadas situaciones, contiene un mandato de desigualdad; $y$, por tanto, es necesaria la desigualdad formal para alcanzar la igualdad real, señalando que dicha diferenciación ha de ser razonable y proporcional a la finalidad perseguida y a la desigualdad existente.

Reconociendo, con ello, el llamado "derecho desigual igualatorio» (tal y como lo define la STC 229/1992, de 14 de diciembre), con el fin de conseguir la igualdad real y efectiva -(art.9.2)- de los colectivos históricamente marginados siempre y cuando dicho tratamiento jurídico diferenciado igualatorio cumpla con los requisitos de razonabilidad o justificación razonable, temporalidad y proporcionalidad. Reconociendo expresamente la referida STC 229/1992, en su Fundamento Jurídico 2, que "la consecución del objetivo igualatorio entre hombres y mujeres permite el establecimiento de un derecho desigual igualatorio, es decir, la adopción de medidas reequilibradoras de situaciones sociales discriminatorias, preexistentes para lograr una sustancial y efectiva equiparación entre las mujeres, socialmente desfavorecidas, y los hombres para asegurar el goce efectivo del derecho a la igualdad por parte de la mujer».

Por lo tanto, para conseguir la igualdad es necesario tratar de forma diferente situaciones iguales. Aunque teniendo en cuenta que no existe reconocido constitucionalmente un derecho subjetivo de trato diferente, ni tan siquiera derivado del articulo 9.2, que no es susceptible de recurso de amparo. De esta forma se ha pronunciado el Tribunal Constitucional, entre otras, en las Sentencias 181/2000, 21/2001, de 29 de enero, 49/2002, de 25 de febrero y 156/2003, de 15 de septiembre, que «es doctrina constitucional reiterada que el derecho a 
la igualdad que consagra el artículo $14 \mathrm{CE}$ ni otorga un derecho a la desigualdad de trato, ni ampara la falta de distinción entre supuestos desiguales, ya que no existe ningún derecho subjetivo al trato normativo desigual, siendo ajeno al ámbito de este precepto la llamada discriminación por indiferenciación».

En consecuencia, podemos afirmar que aunque el art. 9.2 CE resulta vinculante para los poderes públicos, su cumplimiento por parte de los que tienen capacidad normativa obedecerá a criterios de oportunidad política, de tal forma que la adopción de medidas correctoras de situaciones de desigualdad de hecho nunca podrá ser de naturaleza judicial, como resultado del recurso a la jurisdicción ordinaria ni tampoco a la jurisdicción constitucional.

\section{TRATAMIENTO JURÍDICO DIFERENCIADO Y MEDIDAS DE ACCIÓN POSITIVA}

Por lo tanto, para la consecución de la igualdad material, es posible establecer tratamientos jurídicos formalmente desiguales, lo que conecta con las llamadas medidas de acción positiva, utilizadas para paliar situaciones de desigualdad arraigadas en la sociedad.

Aunque sin olvidar que no todos los tratamientos diferenciados orientados a la consecución de la igualdad real o material pueden catalogarse como acciones positivas, constituyendo éstas sólo una especie de aquéllos. A este respecto, Mar Esquembre afirma «que el tratamiento jurídico diferenciado consistente en las denominadas medidas de igualación positiva o prestaciones diferenciadas se corresponderían con el objetivo de la eliminación de la discriminación intragrupal (dentro de grupo, pero entre individuos), mientras que el tratamiento jurídico diferenciado consiste en medidas de acción positiva se corresponderían con el objetivo de la eliminación de la discriminación intergrupal (entre grupos)».

Lo cierto es que existe una gran confusión terminológica y conceptual sobre las llamadas acciones positivas, ya que cualquier medida tendente a la consecuencia de la igualdad, aunque sea entre individuos, es catalogada como acción positiva, obviando que las mismas tienen la finalidad de eliminar la discriminación intergrupal y no intragrupal.

Siguiendo a M.A. Martín Vida, las medidas de acción positiva pueden definirse como "todas aquellas medidas, diversas en sus manifestaciones, que tienen como destinatarios directos a personas que están o han estado discriminadas o que se hallan en una situación de desventaja estructural como consecuencia de su pertenencia a un cierto colectivo, pertenencia determinadas por la posesión de algún rasgo completamente inmutable e íntimamente ligado, en tanto que definitorio de su identidad, a su dignidad como seres humanos, y que persiguen poner fin a esa situación de desventaja estructural, reducir los niveles de des-

4. ESOUEMBRe VALDES, Mar: Fundamentos de la discriminación positiva en Europa y España. En especial, en la Administración Publica, Alicante, Agencia Local de Desarrollo Económico y Social de Alicante, 2004 , p. 61. 
igualdad entre dichos colectivos (y sus miembros) y el resto de la sociedad, y alcanzar mayores cuotas de igualdad real dentro de la comunidad $»^{5}$.

Por lo que se hace necesaria una clasificación de las medidas de acción positiva, a fin de determinar su admisibilidad en el ordenamiento jurídico. A este respecto, Mar Esquembre realiza la siguiente clasificación de las medidas de acción positiva ${ }^{6}$ :

- "Las medidas de concienciación: son generalmente medidas de formación o de carácter publicitario que pretender crear un estado de oposición o una sensibilización del problema. Por ejemplo: las campañas de publicidad para la igualdad sexual, el fomento de cursos de especialización, formación de agentes de igualdad de oportunidades, etc.

- Las medidas de retribución, recompensa o sanción positiva: se trata de medidas que se adoptan tras las realización de la acción querida, como por ejemplo: la asignación de un premio, como puede ser una mención distintiva a las empresas que adopten medidas tendentes a conseguir la igualdad real entre mujeres y hombre, o una exención fiscal, etc.

- Las medidas de facilitación, de impulso o de promoción: son las medidas previas tendentes a la consecución del fin pretendido, que no es otro que el de la eliminación de la discriminación estructural a fin de conseguir una efectiva igualdad real. Dentro de estas, se distingue:

a) Medidas de incentivación: para aumentar las oportunidades competitivas de las personas pertenecientes a colectivos tradicionalmente desfavorecidos; como por ejemplo: subvenciones, becas, etc.

b) Medidas de discriminación inversa o positiva en sentido amplio: se aplican en situaciones de particular escasez e indivisibilidad del bien que se pretende adjudicar. La determinación de la proporción de sujetos tradicionalmente marginados que van a beneficiarse de estas medidas puede hacerse por el sistema de cuotas o por el de objetivos numérico. Dichas medidas pueden, a su vez, revestir diferentes modalidades tales como la de asignar una puntuación extra junto al mérito, a los miembros del colectivo desfavorecido, las medidas de desempate, o finalmente las medidas de trato diferencial.

Nuestra actual Constitución no contiene una referencia específica a las medidas de acción positiva, a diferencia de lo que ocurre en otros textos constitucionales europeos. Así por ejemplo, en Alemania, tras la reforma de la Ley Fundamental de Bonn que se realizó en el año 1994, se añadió un inciso final al apartado 2 del articulo 3, disponiendo expresamente que: «hombres y mujeres gozan de los mismos derechos. El estado favorecerá la realización efectiva de la igualdad entre hombres y mujeres y actuará con el fin de eliminar las desigualdades existentes».

5. MARTÍN VIDA, Ma Ángeles: Fundamento y límites constitucionales de las medidas de acción positiva, Madrid, Civitas, 2003, pp. 39-40.

6. ESQuembre Valdés, Mar: Op. cit. 
También Austria modificó su Ley Constitucional Federal en el año 1998, estableciendo en el apartado 2 de su artículo 7 que «La Federación, las provincias y las comunidades locales asumen un compromiso a favor de la igualdad real entre hombres y mujeres. Se admiten las medidas orientadas a promover la igualdad de hecho de hombres y mujeres, en especial mediante la eliminación de las desigualdades facticas existentes».

En el mismo sentido, tanto la Constitución finlandesa de 1995, como la Ley Constitucional sueca de 1975 o la reforma de la Constitución de Bélgica realizada en febrero del 2002, hacen referencia a la admisiblidad de medidas orientadas a lograr la igualdad real de las mujeres.

Pero a pesar de no existir referencia alguna en nuestro texto constitucional a la admisibilidad de medidas de acción positiva a favor de colectivos desfavorecidos, lo cierto es que éstas si han sido reconocidas legalmente, aunque de momento únicamente destinadas a los discapacitados. En concreto, en la Ley $51 / 2.003$, de 2 de diciembre, de igualdad de oportunidades, no discriminación y accesibilidad universal de las personas con discapacidad, donde en el párrafo segundo de su articulo 1, en el que se concreta el objeto de la misma, se señala que "se entiende por igualdad de oportunidades la ausencia de discriminación, directa o indirecta, que tenga su causa en una discapacidad, así como la adopción de medidas de acción positiva orientadas a evitar o compensar las desventajas de una persona con discapacidad para participar plenamente en la vida política, económica, cultural y social».

Pero a pesar de ese escaso apoyo constitucional, el Tribunal Constitucional ha admitido la diferencia de trato a favor de la mujer, partiendo siempre de la cláusula de interdicción de la discriminación, por considerar que tal interdicción, para ser efectiva en la realidad, necesitaba la concesión de ventajas al sexo femenino, es decir, acciones positivas por parte de los poderes públicos.

Resoluciones de este tipo se pueden encontrar en la jurisprudencia constitucional a partir de 1987. En ellas, se ha venido admitiendo que el remedio de discriminaciones, históricamente arraigadas en la sociedad, de grupos concretos -específicamente, del sexo femenino- pueden justificar acciones positivas, esto es, medidas que tiendan a corregir situaciones desfavorables concediendo determinadas ventajas a los sectores desfavorecidos. Aceptando el Tribunal Constitucional que la discriminación de la mujer es un hecho histórico que ha situado a las mujeres en una posición de inferioridad social y jurídica.

En estos casos de discriminación, la acción positiva se legitima no en función de las características individuales de la persona beneficiaria, sino en función de su pertenencia a un colectivo discriminado: lo que persigue es suprimir aquellas circunstancias de carácter social general que llevan a que los componentes de un grupo determinado se encuentren, como regla general, sometidos a un trato social desfavorable.

Por ello, podemos afirmar que las acciones positivas se encuentran legitimadas en nuestro ordenamiento jurídico, de acuerdo con la interpretación que del concepto de igualdad ha desarrollado el Tribunal Constitucional, entre otras, en las siguientes sentencias: 
- S.T.C. 128/87, de 16 de julio: Reconoce como no discriminatorio para los varones, la percepción de cierta cantidad mensual en concepto de gastos de guardería limitado a las mujeres con responsabilidades familiares, admitiendo la discriminación indirecta, tendente a equilibrar el mercado laboral, eliminando los obstáculos que se han interpuesto históricamente en el acceso de las mujeres al trabajo. Destacando en su Fundamento Jurídico 10 que «La diferencia reside en que existe una innegable y mayor dificultad para la mujer con hijos de corta edad para incorporarse al trabajo o para permanecer en él, dificultad que tiene orígenes muy diversos, pero que coloca a esta categoría social en una situación de hecho claramente desventajosa respecto a los hombres en la misma situación. En tanto, pues, esta realidad perdure, no pueden considerarse discriminatorias las medidas tendentes a favorecer el acceso al trabajo de un grupo en situación de clara desigualdad social, y que traten de evitar, facilitando el empleo de guardería, que una práctica social discriminatoria se traduzca en un apartamiento del trabajo de la mujer con hijos pequeños».

- S.T.C. 19/89, de 31 de enero, en este supuesto el Tribunal Constitucional declara como no discriminatoria la diferenciación de porcentajes aplicables a las pensiones de jubilación anticipadas en el sector textil aplicables al caso enjuiciado, que establecían una sensible diferencia entre hombres y mujeres cuando la jubilación se producía entre los sesenta y los sesenta y cuatro años (la de la mujer podía llegar a un $80 \%$ del salario regulador y la del varón podía alcanzar como máximo el 70\%). Reconociendo en su Fundamento Jurídico 5 «que la diferencia de trato consagrada en los Estatutos de la Mutualidad Laboral del sector textil no tenía por objeto colocar al trabajador varón en peores condiciones al momento de su jubilación, sino más bien compensar de algún modo la situación de inferioridad que, laboral y socialmente, venía padeciendo el personal femenino".

- S.T.C. 28/1.992, de 9 de marzo: Asimismo en esta sentencia el Tribunal Constitucional considera no discriminatorio la compensación económica por el uso del transporte nocturno que el Convenio Colectivo de la Compañía Telefónica Nacional de España concedía al personal femenino. Destacando en su Fundamento Jurídico 3 que «este Tribunal ha entendido que la referencia al sexo en el art. 14 implica también la decisión constitucional de acabar con una histórica situación de inferioridad atribuida a la mujer también en el ámbito del empleo y las condiciones de trabajo, por lo que son constitucionalmente legitimas aquellas medidas que tienden a compensar una desigualdad real de partida, de modo que el precepto constitucional que prohíbe a discriminación por razón de sexo ha de ser interpretado sistemáticamente con otro preceptos constitucionales, en particular con el art. 9.2 C.E. que obliga a los poderes públicos a promover las condiciones para que la igualdad de las mujeres en relación con los hombres sea real y efectiva». Además, es en esta sentencia cuando, por primera vez, el Tribunal Constitucional utiliza el termino «acción positiva», al afirmar que «la prohibición de discriminación por razón de sexo 
admite la existencia de medias singulares a favor de la mujer, que traten de corregir una situación desigual de partida, como son las medidas de acción positiva o similares».

Pero en todos estos casos examinados, se trataban de "medidas de incentivación", cuyo objetivo consistía en incrementar las oportunidades a colectivos desfavorecidos en la participación del reparto de bienes considerados especialmente valiosos. Pretendiendo con dichas medidas, la igualdad de todas las personas en el punto de partida, lo que en principio no presenta un daño directo y concreto a quien no pertenezca al grupo desfavorecido.

El problema se presenta con otro tipo de medidas acción positiva, como son las "medidas de discriminación inversa", dado que no consisten en un simple reparto de bienes sociales valiosos que sitúen a los miembros del colectivo desfavorecido en un punto de partida similar al que se encuentran los excluidos de dicho colectivo, sino que por el contrario implica un perjuicio para el sujeto excluido del grupo, puesto que ya no se trata de que dicho sujeto no pueda obtener determinados beneficios sino que éste sufre una perdida, que de no haberse tenido en cuenta favorablemente el rasgo, no se hubiera producido.

Estas medidas pueden revestir diferentes modalidades, como:

- Asignar una puntuación extra junto al mérito, a los miembros de colectivo desfavorecido, por su simple pertenencia a dicho colectivo.

- Medidas de desempate o de discriminación inversa racionalizada, también llamadas de cuota flexible. Consisten en adjudicar el bien escaso al miembro del colectivo marginado, cuando concurran circunstancias iguales en los candidatos.

- Medidas de discriminación inversa en sentido estricto o también llamadas de cuota rígida; en las que se establece una preferencia automática para el miembro perteneciente al colectivo desfavorecido.

La determinación de los sujetos del colectivo desfavorecido que van a beneficiarse de los dos últimos tipos de medidas, se puede hacer mediante el "sistema de cuotas», por el que se reserva un número determinado de bienes o porcentaje de los mismos a los miembros del colectivo marginado; o por el de "objetivos numérico", por el que se fija un determinado porcentaje a alcanzar de miembros del colectivo discriminado por un periodo de tiempo determinado.

Un ejemplo de medidas de discriminación inversa lo encontramos en la S.T.C. 269/94, de 3 de octubre, referida a un concurso de acceso a la Administración canaria en el que se estableció una reserva porcentual de plazas para discapacitados, estableciéndose en la convocatoria una diferencia de trato basada en la condición de discapacidad de la persona que perjudicaba a aquellas otras que, obteniendo una puntuación superior, no formaban parte de este colectivo.

En este caso el TC no consideró que se tratase de un supuesto de prohibición de discriminación del art. 14 C., al considerarlo como una exigencia derivada del cumplimiento del mandato contenido en el art. 9.2 C., que reconoce la constitucionalidad de medidas equiparadoras de situaciones sociales de desventaja. Entendiendo, por tanto, que la medida adoptada respondía a una 
finalidad constitucional lo suficientemente deseable como para justificar un trato desigual: la lucha contra la discriminación de los discapacitados, habida cuenta de la dificultad de éstos para el acceso al empleo.

Ésta fue la primera (y, por el momento única) ocasión en la que el Tribunal Constitucional se ha pronunciado acerca de la constitucionalidad de las medidas de discriminación inversa.

La aplicación de medidas de discriminación inversa en el caso de las mujeres, supondría el establecimiento de criterios a favor de la mujer en situaciones de competición abierta entre individuos de ambos sexos. Pero lo cierto, es que el Tribunal Constitucional no se ha pronunciado sobre la admisibilidad de medidas de discriminación inversa a favor de las mujeres.

\section{LOS RECIENTES AVANCES LEGISLATIVOS EN MATERIA DE IGUALDAD}

En el año 2004, se aprobó una importantísima y muy necesaria norma de protección de la mujer victima de actos violentos. Se trata de la Ley de protección integral contra la violencia de genero, aprobada por la Ley Orgánica 1/2004, de 28 de diciembre.

La violencia contra las mujeres se produce en el núcleo familiar, pero ha dejado de ser una cuestión privada para pasar a ser un problema social inaceptable, que no debe quedar en ningún caso impune, lo que requiere la actuación efectiva de los poderes públicos. De esta forma, la propia Exposición de Motivos de la referida ley, comienza afirmando que "La violencia de género no es un problema que afecte al ámbito privado. Al contrario, se manifiesta como el símbolo más brutal de la desigualdad existente en nuestra sociedad. Se trata de una violencia que se dirige sobre las mujeres por el hecho mismo de serlo, por ser consideradas, por sus agresores, carentes de los derechos mínimos de libertad, respeto y capacidad de decisión».

En concreto el ámbito de la Ley abarca tanto los aspectos preventivos, educativos, sociales, asistenciales y de atención a las victimas, como toda la normativa civil que incide en el ámbito familiar, así como la respuesta punitiva que deben recibir todas las manifestaciones de violencia contra las mujeres. Destacando en su artículo 1, que la misma tiene por objeto «actuar contra la violencia que, como manifestación de la discriminación, la situación de desigualdad y las relaciones de poder de los hombres sobres las mujeres, se ejerce sobre éstas por parte de quienes sean o hayan sido sus cónyuges o de quienes estén o hayan estado ligados a ellas por relaciones similares de afectividad, aun sin convivencia».

Pero a pesar de la importancia de dicha Ley, y de las medidas que en ella se han aprobado, la violencia contra las mujeres continua, y según confirman los datos, todavía con mas virulencia. El principal problema radica en la consideración por parte del hombre de su superioridad sobre la mujer, y por tanto la sumisión de ésta, lo que a su entender le legitima a actuar de forma violenta hacia ella. Sin duda este drama es el fruto de un sistema patriarcal todavía arraigado en nuestra sociedad, que debe ser definitivamente extinguido. 
Además, de la referida Ley, a corto plazo, parece vislumbrarse un futuro prometedor en la lucha a favor de la igualdad, con la futura Ley Orgánica para la igualdad efectiva de mujeres y hombres, que se encuentra en fase de tramitación parlamentaria. Desde luego no va a ser la panacea universal, pero sí un paso importante en la lucha por conseguir la igualdad de todas las personas.

En la Exposición de Motivos de esta ley, se reconoce expresamente que «resulta necesaria una acción normativa dirigida a combatir todas las manifestaciones aún subsistentes de discriminación, directa o indirecta, por razón de sexo y a promover la igualdad real entre mujeres y hombres, con remoción de los obstáculos y estereotipos sociales que impiden alcanzarla».

Para ello la Ley tiene como principales ejes de actuación: la prevención de las conductas discriminatorias, la previsión de políticas activas para hacer efectivo el principio de igualdad, proyección general del principio de igualdad en los diferentes ámbitos normativos, la ordenación general de las políticas públicas bajo la óptica del principio de igualdad, la adopción de medidas positivas con el fin de alcanzar la igualdad efectiva de mujeres y hombres, establecimiento de medidas de promoción de la igualdad efectiva en las empresas privadas, la corrección de la desigualdad en el ámbito de las relaciones laborales, la promoción de medidas concretas a favor de la igualdad en las empresas, asegurar una representación equilibrada de mujeres y hombres en órganos y cargos de responsabilidad, etc.

En suma, lo que se pretende con dicha norma, es hacer efectiva la igualdad real de mujeres y hombres, mediante la eliminación de cualquier discriminación contra la mujer, en cumplimiento de lo previsto en los artículos 9.2 y 14 .

También está prevista la aprobación del Proyecto de Ley de promoción de la autonomía personal y atención a las personas en situación de dependencia, que tiene por objeto regular las condiciones básicas que garanticen el derecho a la promoción de la autonomía personal y atención a las personas en situación de dependencia, mediante la creación de un Sistema Nacional de Dependencia con la colaboración y participación de todas las Administraciones Publicas. Y ello, como se hace constar en la Exposición de Motivos, debido a que "La atención a este colectivo de población se convierte, pues, en un reto ineludible para los poderes públicos, que requiere una respuesta firme, sostenida y adaptada al actual modelo de nuestra sociedad. No hay que olvidar que, hasta ahora, han sido las familias, y en especial las mujeres, las que tradicionalmente han asumido el cuidado de las personas dependientes, constituyendo lo que ha dado en llamarse el «apoyo informal». Los cambios en el modelo de familia y la incorporación progresiva de las mujeres al mercado de trabajo introducen nuevos factores en esta situación que hacen imprescindible una revisión del sistema tradicional de atención para asegurar una adecuada capacidad de prestación de cuidados a aquellas personas que los necesitan.»

El desarrollo de toda esta normativa, sin duda nos hará avanzar en el camino de la igualdad, permitiéndonos alcanzar una igualdad real y efectiva de mujeres y hombres, eliminando cualquier tipo de discriminación contra la mujer y dando cumplimiento, con ello, al mandato de nuestra actual Constitución. 
Pero finalmente cabe preguntarse ¿qué ocurrirá en el ámbito privado?, ¿llegará algún día esa igualdad de mujeres y hombres también al ámbito familiar?, ¿las mujeres y los hombres compartirán por igual las tareas de cuidado familiar y de trabajo doméstico?, ¿seremos capaces de superar el modelo de familia paternalista, avanzando en la corresponsabilidad de mujeres y hombres?

Aunque el panorama jurídico nos invita al optimismo, creo que tardaremos bastante tiempo en cambiar muchas de estas conductas, que quedan fuera de la posibilidad de regulación legal. Sólo espero que la generación de mi hijo lea estas líneas con el mismo asombro que yo sentía cuando descubrí, por ejemplo, que las mujeres en España no tuvimos derecho a votar hasta 1931.

\section{REFERENCIAS BIBLIOGRÁFICAS}

BARRERE UNZUETA, $M^{a}$ Ángeles: Discriminación, derecho antidiscriminatorio y acción positiva a favor de las mujeres, Madrid, Civitas, 1997.

Balaguer, $\mathrm{M}^{a}$ Teresa: Mujer y Constitución. La construcción jurídica del género, Madrid, Feminismos, 2005.

ESQUEMBRE VALDES, Mar: Fundamentos de la discriminación positiva en Europa y España. En especial, en la Administración Publica, Alicante, Agencia Local de Desarrollo Económico y Social de Alicante, 2004.

GIMENEZ GLUCK, David: Una manifestación polémica del principio de igualdad: acciones positivas moderadas y medidas de discriminación inversa, Valencia, Tirant Lo Blanch, 1999.

LÓPEZ GUERRA, Luis: Igualdad, no discriminación y acción positiva en la Constitución de 1978, en Mujer y Constitución en España, Madrid, Centro de Estudios Políticos y Constitucionales, 2000.

MARTín VIDA, Ma Ángeles: Fundamento y limites constitucionales de las medidas de acción positiva, Madrid, Civitas, 2003.

- "Modelos de medidas de acción positiva en los países miembros de la Unión Europea», Teoría y Realidad Constitucional, $12-13$ (2 semestre 2003-1 semestre 2004), pp. 321-349.

Rodríguez PiñeIro, M. y Fernández López, M.F.: Igualdad y discriminación, Madrid, Tecnos, 1986.

VenturA, Asunción: Las Mujeres y la Constitución Española de 1978, Madrid, Instituto de la Mujer, 1999. 